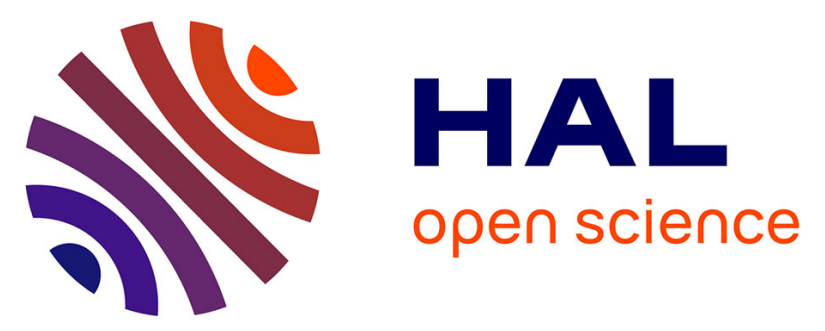

\title{
One dose of a porcine circovirus 2 subunit vaccine induces humoral and cell-mediated immunity and protects against porcine circovirus-associated disease under field conditions \\ Paolo Martelli, Luca Ferrari, Marina Morganti, Elena de Angelis, Paolo Bonilauri, Stefano Guazzetti, Antonio Caleffi, Paolo Borghetti
}

\section{To cite this version:}

Paolo Martelli, Luca Ferrari, Marina Morganti, Elena de Angelis, Paolo Bonilauri, et al.. One dose of a porcine circovirus 2 subunit vaccine induces humoral and cell-mediated immunity and protects against porcine circovirus-associated disease under field conditions. Veterinary Microbiology, 2011, 149 (3-4), pp.339. 10.1016/j.vetmic.2010.12.008 . hal-00683505

\section{HAL Id: hal-00683505 https://hal.science/hal-00683505}

Submitted on 29 Mar 2012

HAL is a multi-disciplinary open access archive for the deposit and dissemination of scientific research documents, whether they are published or not. The documents may come from teaching and research institutions in France or abroad, or from public or private research centers.
L'archive ouverte pluridisciplinaire HAL, est destinée au dépôt et à la diffusion de documents scientifiques de niveau recherche, publiés ou non, émanant des établissements d'enseignement et de recherche français ou étrangers, des laboratoires publics ou privés. 


\section{Accepted Manuscript}

Title: One dose of a porcine circovirus 2 subunit vaccine induces humoral and cell-mediated immunity and protects against porcine circovirus-associated disease under field conditions

Authors: Paolo Martelli, Luca Ferrari, Marina Morganti, Elena

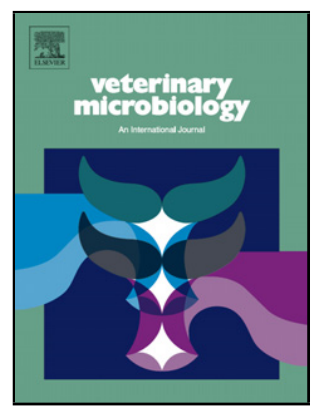

De Angelis, Paolo Bonilauri, Stefano Guazzetti, Antonio

Caleffi, Paolo Borghetti

PII:

S0378-1135(10)00581-X

DOI: doi:10.1016/j.vetmic.2010.12.008

Reference:

VETMIC 5120

To appear in: $\quad$ VETMIC

Received date: $\quad 3-8-2010$

Revised date: $\quad 18-11-2010$

Accepted date: $\quad 7-12-2010$

Please cite this article as: Martelli, P., Ferrari, L., Morganti, M., De Angelis, E., Bonilauri, P., Guazzetti, S., Caleffi, A., Borghetti, P., One dose of a porcine circovirus 2 subunit vaccine induces humoral and cell-mediated immunity and protects against porcine circovirus-associated disease under field conditions, Veterinary Microbiology (2010), doi:10.1016/j.vetmic.2010.12.008

This is a PDF file of an unedited manuscript that has been accepted for publication. As a service to our customers we are providing this early version of the manuscript. The manuscript will undergo copyediting, typesetting, and review of the resulting proof before it is published in its final form. Please note that during the production process errors may be discovered which could affect the content, and all legal disclaimers that apply to the journal pertain. 
$7 \quad{ }^{1}$ Department of Animal Health, University of Parma, Parma, Italy

$8 \quad{ }^{2}$ IZSLER, Reggio Emilia, Italy

$9{ }^{3}$ ASL, Reggio Emilia, Italy

$10{ }^{4}$ Vet Practitioner, Mantova, Italy

12 *Corresponding author:

13 Prof. Paolo Martelli

14 Department of Animal Health

15 University of Parma

16 Via del Taglio, 10

1743126 Parma, Italy

18 Tel +39-0521-032698; Fax +39-0521-032692; E-mail: paolo.martelli@unipr.it

$19{ }^{\mathrm{a}}$ These authors contributed equally to this work. 


\section{ABSTRACT}

This study investigated the efficacy of a one-dose porcine circovirus 2 (PCV2) subunit

vaccine based on the PCV2 Cap protein expressed in a baculovirus system on two different farms at which a history of porcine circovirus-associated disease (PCVD) was present. Morbidity, mortality, average daily weight gain, carcass weight, PCV2 load in serum and vaccine immunogenicity were assessed. Serology to porcine reproductive and respiratory syndrome virus (PRRSV) and Mycoplasma hyopneumoniae was performed. A double-blind, randomised, and controlled field trial was performed distributing 818 piglets between two treatment groups. At inclusion (weaning at 21 \pm 3 days of age), 408 animals (group B) received a 2-mL intramuscular dose of Porcilis $\mathrm{PCV}^{\circledR}$ (vaccinated group). Controls (group A, 410 pigs) received $2 \mathrm{~mL}$ of the adjuvant Diluvac Forte ${ }^{\circledR}$ intramuscularly. Weights were recorded at inclusion and at 12 and 26 weeks of age, and the average daily weight gain (ADWG) was calculated. The carcass weights of the pigs from farm 2 were recorded at slaughter (274 days old). All dead animals (died or culled) underwent autopsy to classify them as PMWS-affected or not. At each farm, blood samples were taken from 22 pigs/group for serologic studies. A beneficial effect was found after vaccination with a single dose of a PCV2 Cap vaccine against PCVD. The vaccination reduced the mortality rate and morbidity, reduced PCV2 viremia and viral load, improved productive performances (e.g. ADWG: +70 g/day between 12 and 26 weeks of age when viremia and the specific disease occurred) as well as carcass weight at slaughter age $(+4.5 \mathrm{~kg})$. These effects were associated with virologic and clinical protection from the immunogenicity of the vaccine measured as activation of both a humoral and a cellular immune response.

Key words: PCV2, PCVD, vaccine efficacy, protection, immune response.

4 Running title: Protection and immunity induced by one-dose PCV2 vaccine. 


\section{INTRODUCTION}

Since the 1990s, porcine circovirus type 2 (PCV2) has been considered the causative agent of the post-weaning multisystemic wasting syndrome (PMWS), one of the major swine diseases worldwide (Allan et al., 1999). Currently, PCV2 is also associated with other diseases, such as porcine dermatitis and nephropathy syndrome, porcine respiratory disease complex, enteritis, and reproductive failure, collectively referred to as porcine circovirus diseases (PCVD) (Segalés et al., 2005). Epidemiologic investigations have shown that porcine reproductive and respiratory syndrome virus (PRRSV), swine influenza virus (SIV), porcine parvovirus, Haemophilus parasuis, Actinobacillus pleuropneumoniae, Streptococcus suis, and Mycoplasma hyopneumoniae are most commonly involved in this syndrome (Chae, 2004). The effects of the virus on the pig immune system have not been fully elucidated. Development of PMWS has been related to an activation of the immune system (Krakowka et al., 2001) or it has been suggested that PCV2 infection may cause immunosuppression, when PMWS occurs (Krakowka et al., 2002; Darwich et al., 2004). Several studies reported that PCV2 infection induces apoptosis of lymphoid cells leading to extensive depletion of lymphocytes.

The control of PCVD is based on management strategies, control of coinfections, and vaccination. The first available commercial PCV2 vaccine is based on an inactivated virus and is registered for use in gilts and sows (Reynaud et al., 2004). At present, three commercial PCV2 vaccines are available for use in piglets from 3-4 weeks of age. Two of these vaccines are based on the PCV2 Cap protein expressed in a baculovirus system (Fachinger et al., 2008; Fort et al., 2008) and the third is based on a chimeric inactivated virus contaning the genomic backbone of the nonpathogenic PCV type 1 but replacing its ORF2 capsid gene by that of PCV2 (Fenaux et al., 2004). The induction of an active immune response against the ORF2-encoded capsid protein has been demonstrated to be the major immunogenic mechanism of protection (Nawagitgul et al., 2002; Blanchard et al., 2003). 
Under field conditions, all PCV2 vaccines currently available on the market are effective showing decreased mortality and cull rates and significantly improving average daily weight gain (ADWG), concomitantly with a decrease of the frequency of coinfections in herds affected with PMWS (Cline at al., 2008; Desrosiers et al., 2009; Fachinger et al., 2008; Horlen et al., 2008; King et al., 2008; Kixmoller at al., 2008; Opriessnig et al., 2008; Tacker et al., 2008; Segalés et al., 2009). PCV2 vaccines are thought to reduce viremia burden and viral-induced specific lymphoid lesions but little is yet known about the mechanism by which they are able to elicit protective immunity (Fachinger et al., 2008; Fort et al., 2008; Horlen et al., 2008). Some studies indicate that the effects are related to total and neutralising antibody responses as well as to cellmediated immunity (Larochelle et al., 2003; Fort et al., 2008; Kixmoller et al., 2008; Opriessnig et al., 2008a, 2008b; Fort et al., 2009a). Most of the published reports have characterised the humoral immunity to PCV2 infection based on the detection of total anti-PCV2 antibodies showing seroconversion that occurs either in subclinically or non-PMWS-infected and PMWSaffected pigs (Rodríguez-Arrioja et al., 2000; Sibila et al., 2004; Grau-Roma et al., 2009). Conversely, the role and mechanisms of the adaptive cell-mediated immune response on controlling PCV2 infection and related diseases has not been studied in depth, particularly under field conditions. Previous reports based on laboratory trials describe that cell-mediated immunity measured by the number of PCV2-specific interferon- $\gamma($ IFN- $\gamma)$-secreting cells (SC) may play a role in mediating viral clearance in combination with neutralising antibodies (Fort et al., 2009a, 2009b) and that the intensity of the cell-mediated immune response may be influenced by the load and the extent of viral replication. These aspects are worth investigating under field conditions both in diseased pigs naturally infected by PCV2 in combination with coinfections and in vaccinated animals showing no or few clinical signs.

The present study was designed to investigate the efficacy of a one-dose PCV2 subunit vaccine based on the PCV2 Cap protein expressed in a baculovirus system at two different farms 
with the presence of PCVD by measuring morbidity, mortality, ADWG (average daily weight gain), carcass weight, and PCV2 viremia load. Vaccine immunogenicity was assessed in terms of development of humoral (total antibodies) and cell-mediated (PCV2-specific IFN- $\gamma$ secreting cells) immune responses. Serology to PRRSV and M. hyopneumoniae was also performed.

\section{MATERIALS AND METHODS}

\subsection{Selection of farms}

The study was conducted in the Northern part of Italy at two farms selected based on their history of PMWS. In both herds, at approximately 15-20 weeks of age, clinical signs of PWMS characterized by wasting, respiratory signs, and growth retardation were mainly associated with a marked increase in the mortality rate. The diagnosis fulfilled the internationally accepted disease case definition, including clinical signs, gross lesions, histopathologic findings, and presence of PCV2 in lymphoid lesions (Segalés et al., 2005). Seropositivity to PCV2 in all categories of animals (replacement gilts, sows, nursery pigs, growers, and fatteners) was demonstrated. Before the start of the study, 5 wasted pigs were autopsied at each farm and the diagnosis was reconfirmed.

Farm 1 was a 900-sow farrow-to-finish herd that, in the previuos year, experienced a $6 \%$ and an $8 \%$ mortality rate in the nursery and fattening periods, respectively. This farm was seronegative for Aujeszky's disease virus (ADV) and seropositive for PRRSV, M. hyopneumoniae and A. pleuropneumoniae. Low titres of antibodies at HI to SIV were obtained from some samples and were inconclusive.

Farm 2 was a three-site farm with 1850 sows experiencing a $2 \%$ and a $10 \%$ mortality rate in the nursery and fattening periods, respectively. Seropositivity to PRRSV and M. hyopneumoniae and seronegativity to ADV were found. 
Sows of both herds were vaccinated for Aujeszky's disease (3 times/year), porcine

119 parvovirus and erysipelas (both at mid-lactation). Piglets were vaccinated to Aujeszky's disease 120 according to the National Control Program.

\subsection{Experimental design}

This study was a double-blind, randomised, controlled field trial performed according to the principles of "Good Clinical Practice” and included 818 piglets (males and females). The day before the inclusion, piglets were identified, double ear-tagged and assigned to the two treatment groups [nonvaccinated/placebo (group A) and PCV2-vaccinated (group B)] as they came to hand sequentially ( $\mathrm{A}-\mathrm{B}-\mathrm{A}-\mathrm{B}-\mathrm{A}-\mathrm{B} \ldots$ etc.). The sequential allocation was continued over the litters. The identification of the sow and the date of birth of the piglets were recorded.

At inclusion (weaning day, $21 \pm 3$ days of age), vaccinated animals (group B) received one dose of a commercial PCV2a-based subunit vaccine (Porcilis PCV ${ }^{\circledR}$, Intervet/Schering-Plough 131 Animal Health, Boxmeer, The Netherlands) containing the PCV2 capsid (Cap) protein expressed in 132 a baculovirus system suspended in an $\alpha$-tocopherol + liquid paraffin -based adjuvant administered 133 intramuscularly $(2 \mathrm{~mL})$ in the right neck muscle according to the recommendation of the 134 manufacturer. The same amount of adjuvant was injected in the same anatomic location in control nonvaccinated pigs (group A). The administration of vaccine and placebo was performed using a double-blind fashion system for both farms. Animals of both groups were injected at weaning and moved to the nursery units. Table 1 lists the details of the study animals at the time of inclusion.

139 the trial, when animals were sent to the slaughterhouse (at approximately 9 months of age). 140 Treatments, housing, husbandry, and feeding were conformed to the European Union Guidelines 141 and identical for both experimental groups at each farm. At each accommodation change, pigs were 142 commingled according to usual farm procedures. 
Pigs were clinically monitored on a weekly basis from the administration of vaccine/placebo

until slaughter. One week after vaccination, pigs were monitored daily for vaccination reactions.

Individual live body weights of all animals enrolled in the study were measured the day before inclusion and at 12 and 26 weeks of age. The average daily weight gain (ADWG) was calculated based on the ADWG of animals being alive at the end of each weighing period. Carcass weight was recorded at the slaughterhouse in pigs from farm 2.

If concomitant treatments (injections) were used, the number of animals treated within each group and the duration of treatment were recorded. The number of relapsed animals (retreatments) were also considered. The number of injections was used as a parameter to evaluate morbidity.

Dead animals or those that had to be euthanised for reasons of animal welfare were recorded daily.

In both herds, at inclusion (day of vaccination, 3 weeks of age), blood samples were collected from 2 piglets of each pluriparous sow litter: one for each treatment group, up to 44 (22 piglets for each treatment group). These piglets were identified by a progressively numbered ear tag.

Moreover, in piglets from farm 1, blood samples were taken at 4 [+1 week post-vaccination (PV)], 5 (+2 weeks PV), 6 (+3 weeks PV), 7 (+4 weeks PV), 9 (+6 weeks PV), 12 (+9 weeks PV), 15 (+12 weeks PV), 16 (+13 weeks PV), 17 (+14 weeks PV), 18 (+15 weeks PV), 19 (+16 weeks PV), 20 (+17 weeks PV), 22 (+19 weeks PV), 26 (+23 weeks PV), and 35 (+32 weeks PV) weeks of age.

In farm 2, blood samples were collected at vaccination ( 3 weeks of age), at 4 (+1 week PV), $6(+3$ weeks PV), 12 (+9 weeks PV), 16 (+13 weeks PV), 18 (+15 weeks PV), 20 (+17 weeks PV), 22 (+19 weeks PV), 24 (+21 weeks PV), 26 (+23 weeks PV), and 35 (+32 weeks PV) weeks of age.

\subsection{Gross pathology, histopathology, and immunohistochemistry studies}


The objective of the pathologic studies was to establish the PMWS diagnosis in all pigs from

168 both farms that died, those needing euthanasia, and runts during the entire study period. These pigs 169 underwent gross pathologic examination and histopathology within 24 hours. Samples from 170 inguinal, mesenteric and mediastinic lymph nodes were removed from necropsied pigs and fixed in $171 \quad 10 \%$ buffered formalin. Fixed samples were processed for routine histopathology and 5- $\mu \mathrm{m}$ thick 172 sections were stained with hematoxylin and eosin to be examined for lesions compatible with 173 PMWS. The diagnosis of PMWS was made when all three criteria of the accepted international 174 individual case definition for the disease (clinical signs, mainly wasting, moderate-to-severe 175 lymphoid lesions, moderate-to-high amounts of PCV2 in those lesions) were present. The amount of PCV2 in tissue samples was also assessed by real-time quantitative PCR (qPCR) using the methods reported by Olvera and colleagues (2004).

Immunohistochemistry for detection of PCV2-specific antigen was performed on formalin-

fixed and paraffin-embedded sections of inguinal, mediastinal, and mesenteric lymph nodes using a rabbit polyclonal antiserum (Sorden, 2000). PCV2 antigen scoring was done by a pathologist in a blinded manner using the score range in accordance with Opriessnig and coworkers (2004).

\subsection{DNA extraction and qPCR to detect PCV2 nucleic acid in tissue samples and serum}

To detect and quantify the PCV2 DNA by PCR, DNA was firstly extracted from $200 \mu 1$ of serum or $200 \mu \mathrm{L}$ of 1:10 phosphate-buffered saline (PBS) homogenate of lymph node tissue, by using TRIzol LS (Invitrogen - San Diego CA- USA) following the manufacturer's instructions. The DNA obtained was suspended in $50 \mu \mathrm{L}$ of diethylpyrocarbonate-treated water. Real-time qPCR was carried out using a LightCycler 1.5 (Roche, Basel - CH).

Real-time qPCR was performed using primers and probes according to Olvera and colleagues (2004). Results of the qPCR were expressed as number of PCV2 genome copies per milliliter of serum or gram of tissue. 


\subsubsection{Detection of PCV2 antibody titres}

The anti-PCV2 antibody titres in sera were determined using a blocking enzyme-linked immunosorbent assay (ELISA). The wells of microtitre plates were coated overnight at $2-8^{\circ} \mathrm{C}$ with baculovirus-expressed PCV2 ORF2 antigen. Subsequently, the plates were washed and blocked with casein buffer at $37^{\circ} \mathrm{C}$ for $1 \mathrm{~h}$. After washing, serial 4 -fold dilutions of the test sera were added. An internal standard serum and a positive and negative standard serum were run in parallel on each plate. The sera were incubated for $1 \mathrm{~h}$ at $37^{\circ} \mathrm{C}$ and the plates were then washed before the addition of a PCV2-specific biotinylated monoclonal antibody (mAb). After $1 \mathrm{~h}$ incubation at $37^{\circ} \mathrm{C}$, plates were washed again and incubated for $45 \mathrm{~min}$ at $37^{\circ} \mathrm{C}$ with avidin-labeled horseradish peroxidase (APO; DAKO A/S, Glostrup - Denmark). After washing, a 3,3',5,5'-tetramethylbenzidine (TMB) substrate solution was added and incubated for $15 \mathrm{~min}$ at room temperature. The reaction was stopped by the addition of $4 \mathrm{~N}$ sulphuric acid and the extinction was read in a photometer fitted with a 450-nm filter (Titertek Multiscan Plus MK 11 - Titertek Instruments Inc., Huntsville, AL - USA) within $15 \mathrm{~min}$ after the reaction was stopped. The raw data were processed and titres were calculated using the Multi-calc program with a cut-off extinction value set at $50 \%$ blocking. The cut-off extinction was calculated from the positive and negative standard serum and titres were expressed as $\log _{2}$.

\subsubsection{Detection of antibody titres to other infections}

The presence of antibodies to PRRSV and sample/positive (S/P) ratio were determined using 214 a commercially available ELISA kit (HerdChek ${ }^{\circledR}$ Porcine Reproductive and Respiratory Syndrome 215 Antibody Test Kit, IDEXX Laboratories, Westbrook, ME, USA) according to the manufacturer's 
instructions. The Herd Check ${ }^{\circledR}$ test bases the sample classification on the S/P ratio, which is defined as (sample OD - negative control OD)/(positive control OD - negative control OD). Sample to 218 positive control ratios $\geq 0.4$ were considered positive. Antibodies to $M$. hyopneumoniae were 219 evaluated by a commercially available ELISA test (Herd Check ${ }^{\circledR} M$. hyopneumoniae, IDEXX Laboratories). The presence of antibodies to $\mathrm{gE}$ glycoprotein of $\mathrm{ADV}$ was measured using a commercially available ELISA kit [HerdChek ${ }^{\circledR}$ PRV g1 (gE) test kit, IDEXX Laboratories] according to the manufacturer's instructions. A commercial ELISA kit (CHEKIT-APP-ApxIV ELISA test kit, IDEXX Laboratories) was used for the detection of antibodies against $A$. pleuropneumoniae. Serology to Swine Influenza was performed by using HI.

\subsubsection{Determination of PCV2-specific IFN- $\gamma$ secreting cells (SC)}

The frequency of IFN- $\gamma$ SC in the peripheral blood of pigs was determined according to Martelli and colleagues (2009). Peripheral blood mononuclear cells (PBMC) were isolated by Histopaque$1.077^{\circledR}$ gradient and plated at $2 \times 10^{5}$ cells/well in RPMI-1640 supplemented with $10 \%$ foetal bovine serum (FBS) into 96-well plates (MultiScreen ${ }^{\circledR}{ }_{\mathrm{HTS}}$-IP MSIPS4510 - Millipore) coated overnight at $4^{\circ} \mathrm{C}$ with $10 \mu \mathrm{g} / \mathrm{mL}$ anti-pig IFN- $\gamma$ mAb (P2G10, BD, Biosciences, Franklinlakes, NJ USA) and blocked with RPMI-1640+10\% FBS for $2 \mathrm{~h}$ at $37^{\circ} \mathrm{C}$. For the in vitro antigen recall, a whole PCV2 strain (I12/11) at 0.1 multiplicity of infection (MOI) was used as stimulus, in RPMI$1640+10 \% \mathrm{FBS}$, for $20 \mathrm{~h}$ at $37^{\circ} \mathrm{C}, 5 \% \mathrm{CO}_{2}$. In all samples, $\mathrm{PBMC}$ were $>98 \%$ viable as confirmed by Trypan blue exclusion. Afterward, plates were incubated for $1 \mathrm{~h}$ at $37^{\circ} \mathrm{C}$ with $0.5 \mu \mathrm{g} / \mathrm{mL}$ anti-pig IFN- $\gamma$ biotin-labeled mAb (P2C11, BD) and then with 1:750 alkaline phosphatase-conjugated antibiotin $\mathrm{mAb}$ in $\mathrm{PBS}+0.5 \% \mathrm{BSA}$. Plates were finally incubated for 7 min with a BCIP/NBT solution

237 (BioRad, Hercules, CA - USA) and the reaction was stopped with distilled water. The frequency of 238 PCV2-specific IFN- $\gamma$ SC was determined using an AID ${ }^{\circledR}$ ELISpot Reader (AID ${ }^{\circledR}$ ELISpot Software 239 v.3.5). As a positive control, $1 \times 10^{5} \mathrm{PBMC} /$ well were incubated with phytohemagglutinin $(10$ 
$240 \mu \mathrm{g} / \mathrm{ml}$ ); as a negative control, $2 \times 10^{5}$ PBMC were incubated in the absence of antigen (mock 241 stimulus: supernatant of non-PCV2-infected PK-15 cells). The background values (number of spots 242 in negative control wells) were subtracted from the respective counts of the stimulated cells and the 243 immune responses were expressed as number of IFN- $\gamma$ SC per million PBMC (IFN- $\gamma$ SC/10 244 PBMC).

\subsection{Statistical analysis}

To estimate the effect of vaccination on the probability of a pig of becoming viremic, a mixed effect logistic regression model was fitted to take into account the non-independence of the repeated measures on the same subjects and the effect of the sow (litter effect). These two variables were treated as "random effects" in the model, whereas the effect of the farm (two levels), sex, time, and treatment and their interactions were considered as "fixed effects". The effect of the time $\times$ treatment interaction was highly significant $(P=0.0146)$, indicating that these results are not attributable to chance alone. The package "Ime4" was used (Bates and Sarkar, 2007; lme4: linear mixed-effects models using S4 classes, R package version 0.999375-32).

To estimate the effect of vaccination on the probability of a pig suffering from PCVD and being lost, considering the competing risks of dying or being lost from other causes, a stratified Cox proportional hazard model was fitted, according to Putter and coworkers (2007) and Therneau and 257 Grambsch (2000). The model accounted also for the "cluster" effect of the sow ("litter effect") because piglets from the same litter are expected to have similar clinical histories.

The effect of the vaccination on weight gain was evaluated within a mixed effects model, 260 given the hierarchical structure of the experiment (Pinheiro and Bates, 2000). Vaccine efficacy was 261 measured by the proportion of cases that it prevented, comparing disease outcome in the treated 262 versus control groups. Efficacy was presented here as one-risk ratio (the so-called preventive 
fraction), which gives the risk in the vaccinated group as a proportion of the risk in the control group (Kirkwood et al., 2003).

Humoral and cellular immunity, determined as titres of anti-PCV2 antibodies and frequencies of IFN- $\gamma$ SC respectively, were statistically evaluated by using ANOVA (analysis of variance) and Dunnett's test in order to higlight differences between treatment groups and changes over time within the same group throughout the experiment.

\section{RESULTS}

\subsection{Reduction of morbidity and mortality in PCV2-vaccinated animals}

In both herds, clinical signs potentially compatible with PMWS were mainly observed during the fourth and fifth month after vaccination (weeks 16-23 PV). Morbidity was quantified by recording the number of individual antimicrobial treatments (injections) during the duration of this experiment. As shown in Figure 1, unvaccinated animals received more injections during the entire duration of the study; according to the statistical analysis using a Poisson model, the differences were significant $(P<0.0001)$. Specifically, animals belonging to group A (placebo/controls) are expected to receive $30 \%$ more injections as compared to vaccinated pigs [ $95 \%$ confidence interval $\left.\left(\mathrm{CI}_{95 \%}\right): 16-50 \%\right]$. pathologic and virologic investigations to be categorised as PMWS and non-PMWS using the recognised diagnostic criteria. The mortality rates in both groups were comparable before the onset of viremia and all dead animals were not affected by PMWS.

At 15-16 weeks of age and onward in both herds, mortality was associated with PCR positivity to PCV2 and with macroscopic and microscopic lesions referred to as PMWS using the pathologic criteria. The details of the occurrence of mortality categorised as PMWS or non-PMWS on a weekly basis at both farms are shown in Figure 2. 
Among the animals that had to be euthanised or removed because they were runts, after the onset of PCV2 viremia they were removed from the study because of wasting (15 vs. 0 pigs; 290 placebo/control vs. vaccinated), growth retardation (12 vs. 3 pigs, respectively), locomotory 291 disorders (4 vs. 5 pigs, respectively), and intestinal torsions (1 vs. 2, respectively).

Before the onset of viremia, total losses were $7.3 \%$ and $7.8 \%$ and after PCV2 viremia $9.02 \%$ and $0.2 \%$, respectively, in the placebo/control and vaccinated groups. Overall, considering both

294 herds for the study duration, total losses (dead, euthanised, and runts) were $16.03 \%$ and $8.0 \%$ in the 295 placebo/control and vaccinated groups, respectively. The estimated hazard ratio for losses related to 296 PMWS in group B (vaccinated animals) compared with group A (placebo/control) was 0.082 297 (CI $95 \%$ : 0.030-0.229; $P<0.0001$; Figure 3). Under the conditions of this study, according to a 298 stratified Cox proportional hazard model accounting for the non-independence of repeated 299 measurement of the same subject and the effect of the sow (litter effect) and for the competing risks 300 of dying from other causes, the probability of a pig vaccinated with a single dose of the test vaccine 301 at 3 weeks of age suffering from PCVD/PMWS was 12 times less than an unvaccinated control pig. 302 The overall efficacy of the vaccine administered, expressed as preventive fraction was $0.918\left(\mathrm{CI}_{95 \%}\right.$ : 303 0.771- 0.970). The preventive fraction represents and provides the proportion of cases that can be 304 prevented with vaccination compared to the unvaccinated population. 
The ADWG is considered a parameter for measuring the effect of PMWS either in acute or

308 in subclinical cases. Table 2 shows the ADWG in vaccinated and placebo/control animals for the 309 intervals among the three different weighing time points. The ADWG in the first time period (3-12 310 weeks of age) was not significantly different. Differences in the ADWG between the treatment 311 groups were observed during the subsequent time period (12-26 weeks), when the vaccinated 312 animals had $70 \mathrm{~g} /$ day higher weight gain than placebo/control animals $(P<0.001)$. Moreover, the 313 proportion of animals whose body weight was at least $25 \%$ lower than the mean body weight of the 314 respective treatment group at 26 weeks of age was $6.5 \%$ and $2.6 \%$ in placebo/control and 315 vaccinated groups, respectively.

Carcass weights in pigs from farm 2 were recorded at the slaughterhouse, as shown in Table 2. In vaccinated animals, the average carcass weight was $4.5 \mathrm{~kg}$ higher than in placebo/controls $(P<$ 318 0.012).

\subsection{PCV2 viremia}

The course of PCV2 viremia at both farms is shown in Figure 4. A sudden onset of viremia was observed at 16-17 weeks of age at both farms. In farm 1, peak levels of 95-100\% of PCRpositive blood samples from placebo/control animals were reached when animals were 20-22 weeks old. A decline of PCR positivity was detected at 26 weeks. The majority of samples with high viral loads ( $>10^{6}$ DNA copies/mL serum) were observed at 19-22 weeks of age (Figure 4a), and $70 \%$ of 326 the animals had at least one blood sample with a viral load $>10^{7}$ DNA copies/mL. Conversely, in 327 the vaccinated group, the proportion of viremic pigs was significantly lower compared to the placebo/control group; between weeks 19 and 22 of age, $40 \%$ of the animals were viremic, with a viral load never $>10^{6}$ DNA copies/mL serum (Figure $4 \mathrm{~b}$ ). At farm 2, the peak of viremia was 330 observed at 18-20 weeks of age with 95\% PCR-positive pigs; pigs with a high viral load ranged 331 from $55 \%$ to $60 \%$ (Figure $4 \mathrm{c}$ ). Viral burden $>10^{7}$ DNA copies $/ \mathrm{mL}$ was detected in $42 \%$ of blood 
samples from the controls. In the vaccinated group only one blood sample was PCR positive at 18 weeks of age, with a low viral burden $\left(<10^{6}\right.$ DNA copies/mL; Figure $\left.4 d\right)$.

The present data clearly indicate that vaccination against PCV2 induced a statistically significant reduction in the proportion of viremic animals and also of the viral load in the blood for both farms in this study $(P<0.001)$.

\subsection{Serology}

\subsubsection{Serologic response to PCV2 vaccination and infection}

The course of serology for PCV2 in both farms is shown in Figure 5. At inclusion (vaccination day), pigs of both groups had comparable levels of ELISA antibodies due to residual maternally derived antibodies (MDA) of 5.95 and $6.69 \log _{2}$ in placebo/control and vaccinated animals, respectively. The difference was not statistically significant. After vaccination, in placebo/control animals, antibody titres progressively declined, whereas a significant increase was observed in vaccinated pigs so that, starting at 2 weeks PV, the differences between the two groups were statistically significant. Animals in the vaccinated groups showed a continuous increase of total antibody titres, reaching a peak of ELISA antibodies at 6-9 weeks PV, with an average geometric mean ranging from 12 to $13 \log _{2}$. From this time point on, the levels of total antibodies in vaccinated groups slightly decreased even if never below a geometric mean of $6 \log _{2}$. At the last time point of blood sampling before the onset of viremia, the geometric mean of total antibodies in the placebo/control animals were under the cut-off for positivity (set at $2 \log _{2}$ ) in sera of pigs from farm 1 and a little over the limit $\left(3.4 \log _{2}\right)$ in pigs from farm 2.

In approximately $10 \%$ of the sampled population, the antibody titres at inclusion were higher than $8 \log _{2}$. In vaccinated animals these titres showed neither an increase as a consequence of vaccination nor a decline but mantained a steady course over time. In the placebo/control group, the 
decline of maternally derived antibodies in animals with a titre higher than $8 \log _{2}$ reached low levels within 10 weeks approximately (data not shown).

In both farms, after the onset of PCV2 viremia, seroconversion occurred within 2-3 weeks in placebo/control or vaccinated groups so that at 20-22 weeks of age the antibody levels in both groups were comparable (11-12 $\left.\log _{2}\right)$. The geometric mean antibody titres of vaccinated animals at 26 and 35 weeks of age were lower than in placebo/control pigs because of a continuing increase of antibodies in the latter group of animals. At the last sampling of this trial at 35 weeks of age, total ELISA antibodies were above the titre of $10 \log _{2}$ in both treatment groups.

\subsubsection{Serologic response to other infections}

Serologic investigations performed to monitor the most frequently occurring infections in

the herds (PRRSV and M. hyopneumoniae) found that the prevalence of PRRSV infection was $100 \%$ at 12 weeks of age in pigs from farm 1 concomitantly with $M$. hyopneumoniae seroconversion. For this latter antigen, seroprevalence continued to increase in the subsequent period.

At farm 2, at 12 weeks of age, pigs of both groups were positive (100\%) for PRRSV and

still negative for $M$. hyopneumoniae. Seroconversion to $M$. hyopneumoniae started to be detected after 15 weeks of age (data not shown).

In both farms, low titres of antibodies at HI to Swine Influenza Virus were detected in some samples and were inconclusive.

\subsection{Cell-mediated immune response to PCV2-vaccination and infection}

IFN- $\gamma$ PCV2-specific SC increased at 2 weeks after vaccination, reaching a peak 1 week later, with a mean value of $120 \mathrm{IFN}-\gamma \mathrm{SC} / 10^{6} \mathrm{PBMC}$ and remained at approximately the same mean value until 9 weeks of age. In the same period, at 2-3 weeks after vaccination, the number of 
381 animals with a progressively higher individual IFN- $\gamma$ response increased (Figure $6 \mathrm{~b}$ ). In 382 unvaccinated pigs the level of IFN- $\gamma$ PCV2-specific SC remained at basal levels $(<20$ IFN- $\gamma$ PCV2383 specific SC) for the entire PV period (Figure 6a).

After the occurrence of the infection at 15-16 weeks of age, the number of PCV2-specific IFN- $\gamma$ SC in vaccinated animals showed an erratic course with moderate individual increases ranging from 40 to $60 \mathrm{IFN}-\gamma-\mathrm{SC}$ (Figure 6d). Conversely, in placebo/control pigs IFN- $\gamma$ SC showed a significant increase $(P<0.01)$ with mean values of 196 and $244 \mathrm{IFN}-\gamma$ SC at 19 and 20 weeks of age, respectively. The mean values were maintained at high levels (140 IFN- $\gamma$ SC) until 26 weeks of age. It is worth noting that the IFN- $\gamma$-SC response was characterised by a high inter-individual variability, with some pigs showing a very high PCV2-specific secretion (high responders; Figure $6 c)$.

\section{DISCUSSION AND CONCLUSIONS}

This study investigated the efficacy of a commercial PCV2a sub-type based subunit vaccine containing the capsid protein expressed in a baculovirus system under field conditions on clinical, pathologic and virologic outcomes. Aspects of the humoral and cell-mediated immune response were studied. The trial was performed in two large farms where the exposure of the animals to various pathogens such as PCV, PRRSV, M. hyopneumoniae, and commonly detected bacteria was the classical predisposing condition for PCVD (Kawashima et al., 2007). Under the conditions of this study, the onset of the clinical signs related to PCVD, in both herds, occurred during the fifth month of age and PCV2 infection was detected during the same period.

Vaccination with a single dose of the test vaccine administered intramuscularly at 3 weeks 403 of age consistently reduced clinical signs attributed to PCVD as well as mortality and PCV2 viral 404 load and viremia. The vaccine used for this field trial and the schedule of administration had been 
described its efficacy under field conditions. This study sheds light on the effects of this PCV2 vaccine on farms with the presence of PCVD during the fattening period in animals aged 4-5 months, in line with the disease history in both farms. Such effects involved clinical signs and productivity (decreased numbers of pigs needing intramuscular therapy, improvement of ADWG, and decreased mortality) and PCV2 viral load in target organs of dead animals and in blood of sampled pigs in amounts and duration of viremia.

In both herds, PCV2 infection occurred in combination with other pathogens, namely, PRRSV and M. hyopneumoniae as demonstrated by serology. To measure morbidity, the number of individual treatments in unvaccinated and vaccinated animals was recorded for the duration of the study and was significantly higher in the placebo/control group. According to the statistical model applied (Poisson model) unvaccinated animals were expected to receive on average 30\% more injections than vaccinated pigs. Another parameter to evaluate the efficacy of the vaccine under investigation was the comparison of ADWG. Before the onset of PCV2 viremia and associated diseases, from 3 to 12 weeks of age, no differences in ADWG were recorded. Conversely, from 12 to 26 weeks, the period when PCV2 viremia and PCVD occurred, the ADWG in vaccinated pigs was $70 \mathrm{~g} /$ day higher than in controls as a result of the protective effect induced by vaccination. This result is improved compared to results reported in previous studies (Fachinger et al., 2008; Horlen et al., 2008; Kixmoller et al., 2008; Segalés et al., 2009). The proportion of pigs that at 26 weeks of age had a body weight at least $25 \%$ lower than the mean body weight of the respective treatment group was $6.5 \%$ and $2.6 \%$ in placebo/control and vaccinated groups, respectively. Vaccination reduced the overall mortality at both farms; the statistically significant differences were related to a decreased number of pigs suffering from PMWS and showing specific lesions in target tissues. In fact, only 1 of 408 vaccinated pigs died from PMWS. The results show that the probability of a pig vaccinated with a single dose of Porcilis ${ }^{\circledR} \mathrm{PCV}$ at 3 weeks of age dying from PMWS was 12 times less than that of an unvaccinated control pig. Furthermore, the similar 
431 ADWG and mortality rates in both treatment groups within the first 9 weeks after vaccination 432 indicate that the vaccine does not negatively influence the health status of the animals and suggests 433 that the vaccine is well tolerated. All the improved parameters are associated with a significant 434 reduction in the proportion of infected pigs and in the viral load in the blood of the animals. During 435 the period of PCV2 infection (16-26 weeks of age on average), a high number of placebo/control 436 pigs showed high viral loads in serum $\left(>10^{7}\right.$ DNA copies $\left./ \mathrm{ml}\right)$, whereas in vaccinated pigs the 437 duration of viremia and the viral load were markedly lower. In fact, in the placebo/control group, 438 the percentages of viremic pigs with an amount of PCV2 in the blood $\geq 10^{7}$ DNA copies/ml were $43970 \%$ and $42 \%$, for farms 1 and 2, respectively. Conversely, none of the vaccinated pigs had a viral 440 load in the blood as high as this level; it always was $<10^{6}$ DNA copies $/ \mathrm{ml}$. This classification based 441 on the amount of PCV2 load in the blood, namely $<10^{6}$, between $10^{6}$ and $10^{7}$, and $>10^{7}$ DNA 442 copies/ml, is used to categorise pigs as subclinically infected, suspected, and diseased for PCV2associated diseases, respectively (Olvera et al., 2004; Opriessnig et al., 2007). Moreover, the 444 classification can be used for prognostic purposes because pigs with high titres of PCV2 classified 445 as affected with PCVD have a poor prognosis. A well-documented feature of PCV2 piglet vaccination under field conditions is the ability to diminish both the proportion of infected pigs as well as the viral load of infected animals (Fachinger et al., 2008; Horlen et al., 2008; Kixmoller et al., 2008).

The reduction of the number of PCV2-positive pigs and the viral load in vaccinated pigs is associated with the improved ADWG and reduced mortality. The approach based on qPCR is the most practical tool to monitor the efficacy of a vaccine treatment because it can be obtained from live animals (Segalés at al., 2010).

All tested animals were PCV2 negative by qPCR at the time of vaccination so that the antibody titres detected were most likely of maternal origin. However, vaccination of piglets against PCV2 with this vaccine causes a prompt seroconversion independently of the level of MDA when 
the titres of ELISA antibodies are below an observed threshold of $8 \log _{2}$ (approximately $90 \%$ of vaccinated pigs). Over this level, observed in approximately $10 \%$ of the vaccinated population, the antibody titres showed neither an increase as a consequence of vaccination nor a decline, but maintained a steady course over time. Thus, at the time of infection (>16-17 weeks of age) all vaccinated pigs, independently from the level of antibodies at vaccination, were protected showing an ELISA titres $>6 \log _{2}$. Conversely, in placebo/control pigs, either with MDAs $<8 \log _{2}$ at inclusion or with high levels $\left(>8 \log _{2}\right)$, a gradually declining course was detected and reached low levels within a few weeks. At the time of late infection, occurring under the conditions of this study, none of the controls was protected as demonstrated by the high proportion of viremic pigs (100\% and 95\%, respectively, from farm 1 and 2) and by the incidence of clinical signs and mortality.

Using the conditions of this study, we suggest that it is possible to set two different thresholds of ELISA antibodies. When the titre of MDA is $>8 \log _{2}$, detected in approximately $10 \%$ of pigs, seroconversion to vaccination does not occur. Nevertheless, these animals, when infection occured, had ELISA titres $>6 \log _{2}$ thus resulting protected. Conversely, in controls, the highest titres of MDA decline similarly so that, at later exposure to PCV2, the ELISA titres are $<6 \log _{2}$ and the animals are completely susceptible to infection with a high viral load.

These results confirm that high MDA titres do not interfere with the effect of a single dose of the vaccine under investigation (Fort et al., 2008, 2009b; Opriessnig et al., 2008a) and that the vaccine is suitable for immunization of seropositive piglets, conferring clinical and virologic protection even if infection occurs very late after vaccination ( $\geq 4-5$ months). In contrast to the results reported by Kixmoller and colleagues (2008), the significant increase of ELISA antibody titres in vaccinated animals $\geq 3$ weeks $\mathrm{PV}$ allows the use of this serologic investigation and particularly the seroconversion at two subsequent sampling time as a reliable tool to differentiate vaccinated and controls before infection and to evaluate vaccine compliance. However, the very low number of 
vaccinated animals becoming infected do not allow to assess a correlation between ELISA titres and clinical and virological protection.

It is worth noting that under the conditions of this study, PCVD lasted at least until 26 weeks of age and accordingly, the high increase of weight gain in vaccinated animals compared to placebo/controls indicates: a) the especially devastating effects of PCVD if it occurs at late time points (which is more and more often the case under field conditions), b) that passively acquired maternal derived antibodies are not protecting at this age, c) that this vaccine provides a long duration of immunity.

The protective immunity induced by commercial PCV2 vaccines has been studied in terms of development of an effective humoral response, whereas the role of cell-mediated immunity has not been yet elucidated. Some previous laboratory studies by Fort and coworkers (2008, 2009b) demonstrated that during the course of PCV2 infection pigs develop cell-mediated immunity specific to the virus and suggested that the development of PCV2-specific INF- $\gamma$ SC might contribute together with neutralising antibodies to viral clearance. In the present study, we have described the cell-mediated immune response after PCV2 vaccination and subsequent infection and disease under field conditions where coinfections also have a role. Under laboratory conditions, the specific PCV2-associated diseases do not occur in experimentally challenged pigs, whereas under field conditions coinfections as well as other intrinsic or extrinsic factors exacerbate the disease.

This paper demonstrates that a single dose of the test vaccine (PCV2 Cap vaccine) induces a specific cell-mediated immune response with a significant increase of the frequency of IFN- $\gamma$ SC already at 2 weeks after vaccination. This evidence also suggests the contribution of cell-mediated responses in vaccine-induced protection because the protective effect of PCV2 antibodies is titredependent and the sole induction of a humoral response might not guaratee full protection against PCV2 infection (Blanchard et al., 2003; Opriessnig et al., 2009; Fort et al., 2009b). 
After the onset of infection, control pigs showed a marked incresase of IFN- $\gamma \mathrm{SC}$ and at the end of the observation period these high levels of cellular response were associated with a reduction 506 of viremia. This demonstrates that the development of adaptive immunity over the course of the spontaneous PCV2 infection in the field also involves cell-mediated responses. In accordance with the results reported by Fort and colleagues (2009b), IFN- $\gamma$ SC responses are apparently related to viral replication. Thus, in pigs in which PCV2 viral load was low or absent, as occurred more 510 frequently in vaccinated animals, the number of these cells is rather low or is maintained at residual 511 levels as a consequence of the primary activation by vaccination (ranging from 40 to 60 IFN- $\gamma \mathrm{SC}$ ). 512 Conversely, controls exhibiting high levels of viremia and disease consistent with PCV2 513 replications had a higher frequency of IFN- $\gamma$ SC concomitantly with the increase of PCV2 514 antibodies. With PCV2 natural infection, the observed high response in controls with high viral load 515 can be explained by the fact that the IFN- $\gamma$ SC response develops against both Cap and Rep 516 proteins. The intensity of the generated response differs using either the Cap protein or the whole 517 PCV as an in vitro stimulus; IFN- $\gamma$ responses obtained by stimulating PBMC with the whole virus 518 are higher than with the Cap protein, suggesting that infected animals in which PCV2 is replicating 519 might respond strongly to other viral components different from the Cap protein (Fort et al., 2009b). 520 Under the conditions of this study, we cannot exclude that coinfections had a role in modulating the 521 interaction of PCV2 and the adaptive immunity with effects on viral replication and load in vivo and on the onset of the clinical abnormalities.

Based on these observations it seems that the development of the PCV2-specific cellmediated response might help avoid progression of PCV2 infection even if further studies are required to elucidate the inner mechanisms used by cell-mediated immunity to complete viral In conclusion, the present study demonstrates the beneficial effect of vaccination with a single dose of a PCV2 Cap vaccine against PCVD under field conditions. The vaccination reduces 
the mortality rate, morbidity evaluated as number of individual treatments, and PCV2 viremia and viral load, and improves productive performances, namely, daily weight gain as well as carcass weight at the time of slaughter. These effects are strictly associated with virologic and clinical protection as a result of the immunogenicity of the tested vaccine measured as activation of either humoral or a cellular immune response. Furthermore, the similar ADWG and mortality rates in both treatment groups within the first 9 weeks after vaccination, the absence of local reactions and the reduced number of injections in vaccinated animals as compared to placebo/controls in the same time period, indicate that the vaccine does not negatively influence the health status of the animals and suggests that the vaccine is well tolerated.

\section{ACKNOWLEDGEMENTS}

The authors thank Dr. Luca Bonati (University of Parma) for technical support on haematological analysis and Dr. Alberto Ermanno Cevidalli (Intervet/Schering-Plough Animal Health) for cooperation in sampling of the animals. Ph.D. studies of Dr. Marina Morganti are funded by a predoctoral grant of the University of Parma (Italy) in "Experimental and Comparative Immunology and Immunopathology”. This work was supported by a grant from the University of Parma (Italy) FIL 2007 (FIL0797239) and also by Intervet/Schering Plough Animal Health (Boxmeer, The Netherlands).

\section{REFERENCES}

1. Allan, G.M., McNeilly, F., Meehan, B.M., Kennedy, S., Mackie, D.P., Ellis, J.A., et al., 1999. Isolation and characterisation of circoviruses from pigs with wasting syndromes in Spain, Denmark and Northern Ireland. Vet. Microbiol. 66, 115-123. 
2. Bates, D.M., Sarkar, D., 2007. lme4: Linear mixed-effects models using S4 classes, R package version $0.999375-32$.

3. Blanchard, P., Mahe, D., Cariolet, R., Keranflec'h, A., Baudouard, M.A., Cordioli, P., et al., 2003. Protection of swine against post-weaning multisystemic wasting syndrome (PMWS) by

4. Chae, C., 2004. Postweaning multisystemic wasting syndrome: a review of aetiology,

9. Fenaux, M., Opriessnig, T., Halbur, T., Elvinger, F., Meng, X.J., 2004. A chimeric porcine circovirus (PCV) with the immunogenic capsid gene of the pathogenic PCV type 2 (PCV2) cloned into the genomic backbone of the nonpathogenic PCV1 induces protective immunity against PCV2 infection in pigs. J. Virol. 78, 6297-6303.

10. Fort, M., Sibila, M., Allepuz, A., Mateu, E., Roerink, F., Segales, J., 2008. Porcine circovirus type 2 (PCV2) vaccination of conventional pigs prevents viremia against PCV2 isolates of different genotypes and geographic origins. Vaccine 26, 1063-1071. 
11. Fort, M., Sibila, M., Pérez-Martín, E., Nofrarías, M., Mateu, E., Segalés, J., 2009a. One dose of a porcine circovirus 2 (PCV2) sub-unit vaccine administered to 3-week-old conventional piglets elicits cell-mediated immunity and significantly reduces PCV2 viremia in an experimental model. Vaccine 27, 4031-4037.

12. Fort, M., Fernandes, L.T., Nofrarías, M., Díaz, I., Sibila, M., Pujols, J., et al., $2009 b$. Development of cell-mediated immunity to porcine circovirus type 2 (PCV2) in caesareanderived, colostrum-deprived piglets. Vet. Immunol. Immunopathol. 129, 101-107.

13. Grau-Roma, L., Hjulsager, C.K., Sibila, M., Kristensen, C.S., Lopez-Soria, S., Enoe, C., et al., 2009. Infection, excretion and seroconversion dynamics of porcine circovirus type 2 (PCV2) in pigs from post-weaning multisystemic wasting syndrome (PMWS) affected farms in Spain and Denmark. Vet. Microbiol. 135, 272-282.

14. Horlen, K.P., Dritz, S.S., Nietfeld, J.C., Henry, S.C., Hesse, R.A., Oberst, R., et al., 2008. A field evaluation of mortality rate and growth performance in pigs vaccinated against porcine circovirus type 2. J. Am. Vet. Med. Assoc. 232, 906-912.

15. Kawashima, K., Katsuda, K., Tsunemitsu, H., 2007. Epidemiological investigation of the prevalence and features of postweaning multisystemic wasting syndrome in Japan. J. Vet. Diagn. Invest. 19, 60-68.

16. King, D., DuBois, P., Painter, T., Holck, T., Edler, R., Johnson, C., et al., 2008. Biologic and economic benefits of controlling subclinical PCVAD with vaccination. Proceedings of the AASV Congress, pp. 159-162.

17. Kirkwood, B.R., Sterne, J.A.C., 2003. Medical Statistics. Blackwell Science, Oxford, UK, $2^{\text {nd }}$ ed., pp. 454-455.

18. Kixmoller, M., Ritzmann, M., Eddicks, M., Saalmuller, A., Elbers, K., Fachinger, V., 2008. Reduction of PMWS-associated clinical signs and co-infections by vaccination against PCV2. Vaccine 26, 3443-3451. 
19. Krakowka, S., Ellis, J.A., McNeilly, F., Ringler, S., Rings, D.M., Allan, G., 2001. Activation of the immune system is the pivotal event in the production of wasting disease in pigs infected with porcine circovirus-2 (PCV-2). Vet. Pathol. 38, 31-42.

20. Krakowka, S., Ellis, J.A., McNeilly, F., Gilpin, D., Meehan, B., McCullough, K., et al., 2002. Immunologic features of porcine circovirus type 2 infection. Viral Immunol. 15, 567-582.

21. Larochelle, R., Magar, R., D’Allaire, S., 2003. Comparative serologic and virologic study of commercial swine herds with and without postweaning multisystemic wasting syndrome. Can. J. Vet. Res. 67, 114-120.

22. Martelli, P., Gozio, S., Ferrari, L., Rosina, S., DeAngelis, E., Quintavalla, C., et al., 2009. Efficacy of a modified live porcine reproductive and respiratory syndrome virus (PRRSV) vaccine in pigs naturally exposed to a heterologous European (Italian cluster) field strain: clinical protection and cell-mediated immunity. Vaccine 27, 3788-3799.

23. Nawagitgul, P., Harms, P.A., Morozov, I., Thacker, B.J., Sorden, S.D., Lekcharoensuk, C., et al., 2002. Modified indirect porcine circovirus (PCV) type 2-based and recombinant capsid protein (ORF2)-based enzyme-linked immunosorbent assays for detection of antibodies to PCV. Clin Diagn. Lab. Immunol. 9, 33-40.

24. Olvera, A., Sibila, M., Calsamiglia, M., Segalés, J., Domingo, M., 2004. Comparison of porcine circovirus type 2 load in serum quantified by a real time PCR in postweaning multisystemic wasting syndrome and porcine dermatitis and nephropathy syndrome naturally affected pigs. J Virol. Methods 117, 75-80.

25. Opriessnig, T., Thacker, E.L., Yu, S., Fenaux, M., Meng, X.J., Halbur, P.G., 2004. Experimental reproduction of postweaning multisystemic wasting syndrome in pigs by dual infection with Mycoplasma hyopneumoniae and porcine circovirus type 2. Vet. Pathol. 41, 624640. 
26. Opriessnig, T., Meng, X.J., Halbur, P.G., 2007. Porcine circovirus type 2 associated disease: update on current terminology, clinical manifestations, pathogenesis, diagnosis, and intervention strategies. J. Vet. Diagn. Invest. 19, 591-615.

27. Opriessnig, T., Patterson, A.R., Elsener, J., Meng, X.J., Halbur, P.G., 2008a. Influence of maternal antibodies on efficacy of porcine circovirus type 2 (PCV2) vaccination to protect pigs from experimental infection with PCV2. Clin. Vaccine Immunol. 15, 397-401.

28. Opriessnig, T., Madson, D.M., Prickett, J.R., Kuhar, D., Lunney, J.K., Elsener, J., et al., $2008 b$. Effect of porcine circovirus type 2 (PCV2) vaccination on porcine reproductive and respiratory syndrome virus (PRRSV) and PCV2 coinfection. Vet. Microbiol. 131, 103-114.

29. Opriessnig, T., Patterson, A.R., Madson, D.M., Pal, N., Halbur, P.G., 2009. Comparison of efficacy of commercial one dose and two dose PCV2 vaccines using a mixed PRRSV-PCV2SIV clinical infection model 2-3-months post vaccination. Vaccine 27, 1002-1007.

30. Pinheiro, J.C., Bates, D.M., 2000. Mixed-Effects Models in S and S-PLUS, Springer NY.

31. Putter, H., Fiocco, M., Geskus, R.B., 2007. Tutorial in biostatistics: competing risks and multistate models. Stat. Med. 26, 2389-2430.

32. Reynaud, G., Brun, A., Charreyre, C., Desgouilles, S., Jeannin, P., 2004. Safety of a repeated overdose of an inactivated adjuvanted PCV2 vaccine in conventional pregnant filts and sows. Proceedings of the $18^{\text {th }}$ Congress International Pig Veterinary Society (IPVS).

33. Rodríguez-Arrioja, G.M., Segalés, J., Balasch, M., Rosell, C., Quinta, J., Folch, J.M., et al., 2000. Serum antibodies to porcine circovirus type 1 (PCV-1) and type 2 (PCV-2) in pigs with and without postweaning multisystemic wasting syndrome (PMWS). Vet. Rec. 146, 762-764.

34. Segalés, J., Allan, G.M., Domingo, M., 2005. Porcine circovirus diseases. Anim. Health. Res. Rev. 6, 119-142.

35. Segalés, J., Urniza, A., Alegre, A., Bru, T., Crisci, E., Nofrarías, M., et al., 2009. A genetically engineered chimeric vaccine against porcine circovirus type 2 (PCV2) improves clinical, 
pathological and virological outcomes in postweaning multisystemic wasting syndrome affected 653 farms. Vaccine 27, 7313-7321.

654 36. Segalés, J., Urniza, A., Alegre, A., Bru, T., Crisci, E., Nofrarías, M., et al., 2010. A genetically 655 engineered chimeric vaccine against porcine circovirus type 2 (PCV2) improves clinical, 656 pathological and virological outcomes in postweaning multisystemic wasting syndrome affected 657 farms. Vaccine 27, 7313-7321.

658 37. Sibila, M., Calsamiglia, M., Segalés, J., Blanchard, P., Badiella, L., Le Dimna, M., et al., 2004. 659 Use of a polymerase chain reaction assay and an ELISA to monitor porcine circovirus type 2 660 infection in pigs from farms with and without postweaning multisystemic wasting syndrome. 661 Am. J. Vet. Res. 65, 88-92.

662 38. Sorden, S.D., 2000. Update on porcine circovirus and postweaning multisystemic wasting 663 syndrome (PMWS). Swine Health Prod. 8, 133-136.

664 39. Tacker, B., Wilson, W., Francisco, C, Schlueter, R., 2008. Circumvent PCV vaccine: 665 performance evaluation and serological studies update, Proceedings of the AASV Congress, 666 pp. $153-156$.

667 40. Therneau, T.M., Grambsch, P.M., 2000. Modeling Survival Data: Extending the Cox Model. $668 \quad$ New York: Springer. 
674

Farm 1

Farm 2

\begin{tabular}{|c|c|c|c|c|}
\hline & $\begin{array}{l}\text { Group A } \\
\text { (Placebo) }\end{array}$ & $\begin{array}{c}\text { Group B } \\
\text { (Vaccinated) }\end{array}$ & $\begin{array}{l}\text { Group A } \\
\text { (Placebo) }\end{array}$ & $\begin{array}{c}\text { Group B } \\
\text { (Vaccinated) }\end{array}$ \\
\hline Pigs at inclusion & 206 & 205 & 204 & 203 \\
\hline Males - females & $97-109$ & $112-93$ & $109-95$ & $108-95$ \\
\hline Total pigs & \multicolumn{2}{|c|}{411} & \multicolumn{2}{|c|}{407} \\
\hline Litters & \multicolumn{2}{|c|}{43} & \multicolumn{2}{|c|}{40} \\
\hline Weighed at inclusion & 206 & 205 & 204 & 203 \\
\hline Bled at inclusion & 22 & 22 & 22 & 22 \\
\hline
\end{tabular}

675

676 Table 1: Details of the animals under study at the time of inclusion. Group A: placebo/control pigs; 677 group B: PCV2-vaccinated pigs.

678 


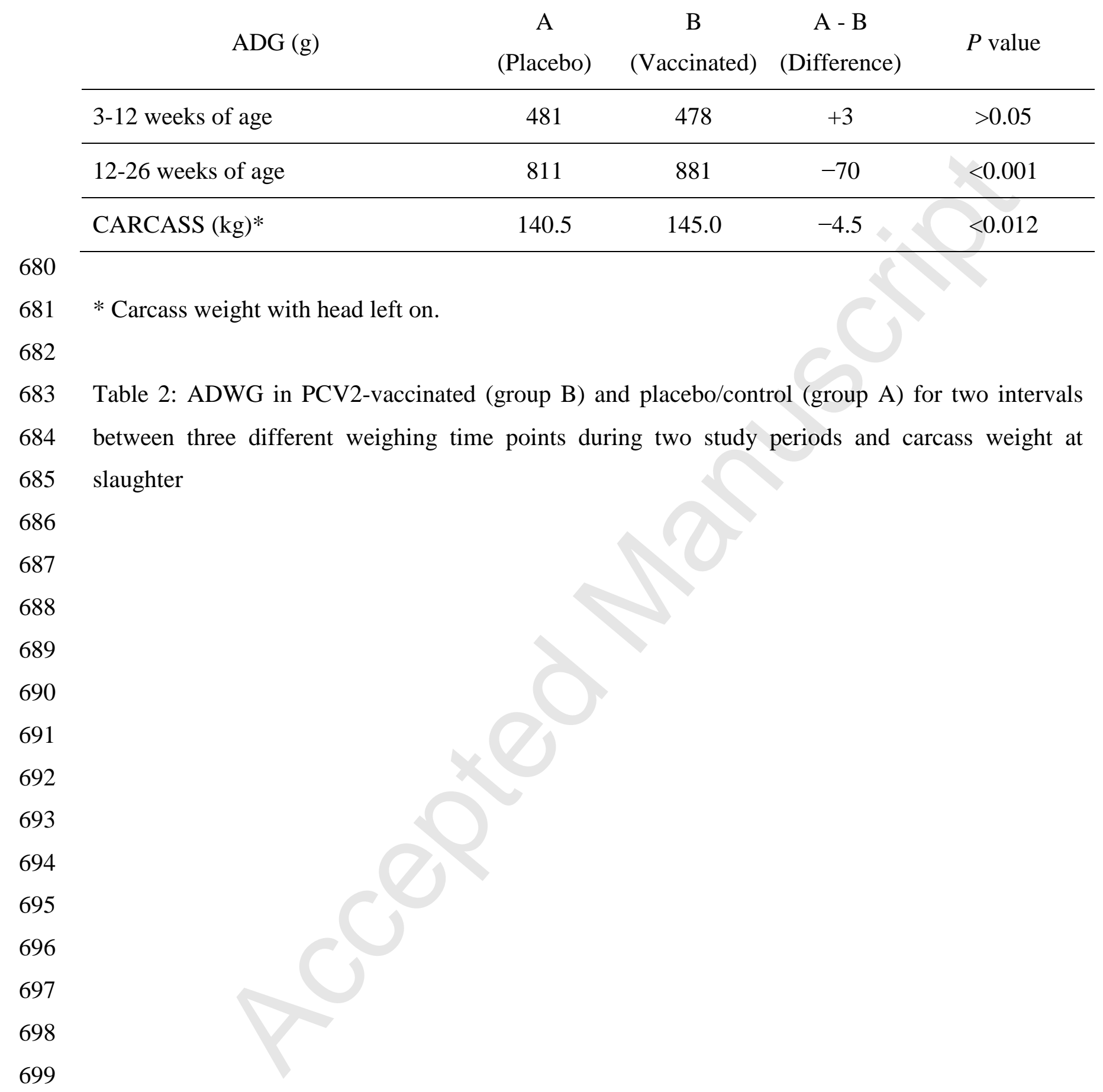




\section{Figure Captions}

Figure 1: Course of morbidity (injections/pigs) in placebo/control (group A) and PCV2-vaccinated

703 (Group B) animals (Poisson model; $P<0.0001$ ).

704 Legend: $\mathrm{X}$ axis: months post-inclusion

Figure 2: Losses due to PMWS and non-PMWS in PCV2-vaccinated and placebo/control pigs of farm 1 (top) and farm 2 (bottom).

Legend: PMWS C: control pigs diagnosed as PMWS-affected; NON PMWS C: control pigs not affected by PMWS; PMWS V: vaccinated pigs diagnosed as PMWS-affected; NON PMWS V: vaccinated pigs not affected by PMWS.

Figure 3: Probability of a pig in the placebo/control (A) and vaccinated (B) groups to be lost 713 because of PCVD and other causes according to the estimated hazard risk over time, in both farms. $714 \quad \mathrm{X}$ axis: days post-inclusion; Y axis: probability

716 Figure 4: Course of viremia over time in placebo/control (a) and PCV2-vaccinated pigs (b) of farm 7171 and farm 2. Data are expressed as number of PCV2 DNA copies/ml of serum.

719 Figure 5: Course of the serologic response to PCV2 (anti-PCV2 antibodies) at farm 1 and farm 2 720 from inclusion ( 3 weeks of age) to the end of the trial (data are expressed as $\log _{2}$ of the geometric 721 mean titres, GMT). 
723 Figure 6: Course of individual IFN- $\gamma$ PCV2-specific SC frequencies in placebo/control and PCV2-

724 vaccinated animals after vaccination at 3 weeks of age ( $a=$ placebo/control; $b=$ vaccinated $)$ and after 725 natural exposure to PCV2 (c= placebo/control; $d=$ vaccinated), in both farms. 


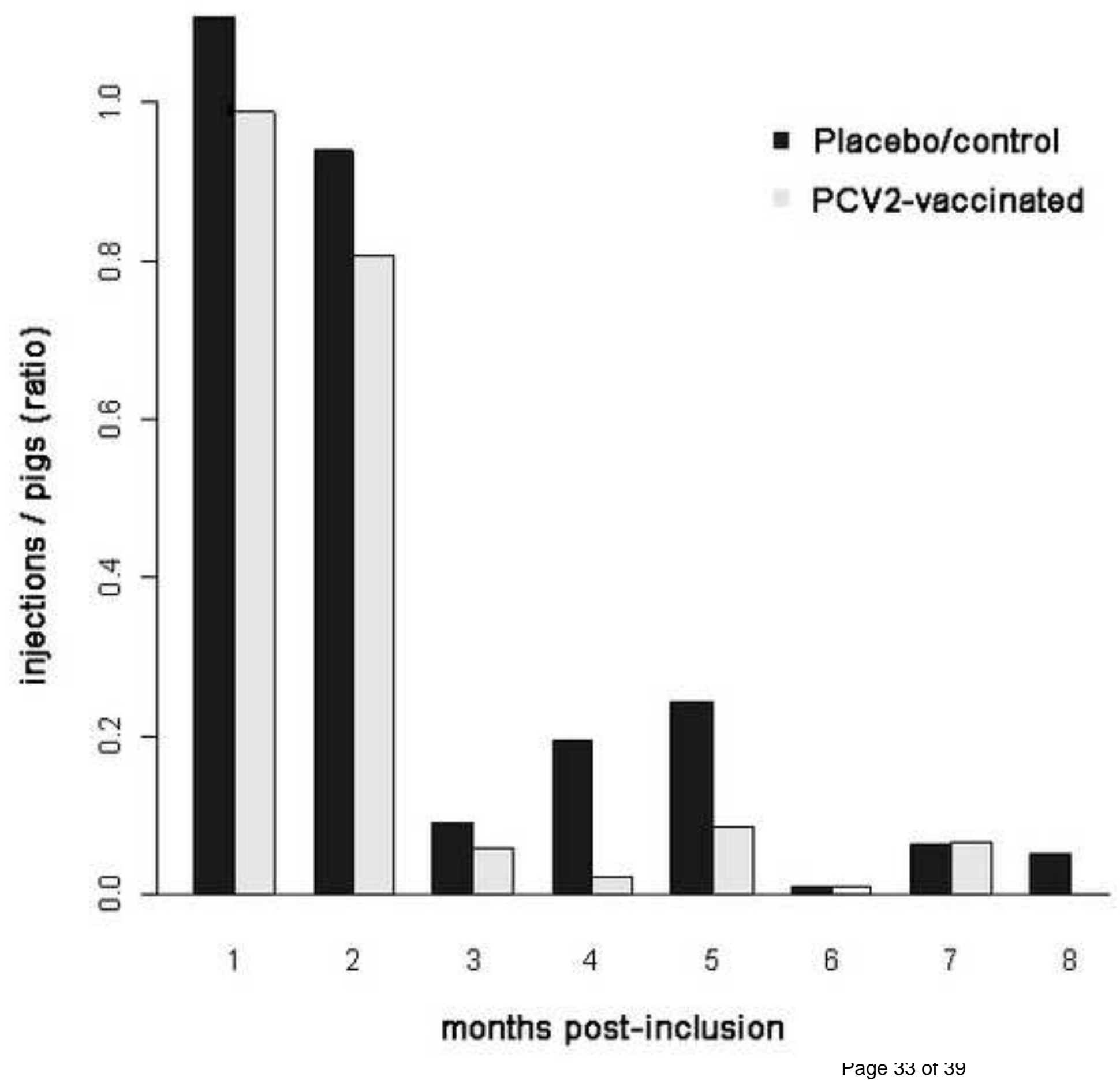

rage 33 or $3 y$ 

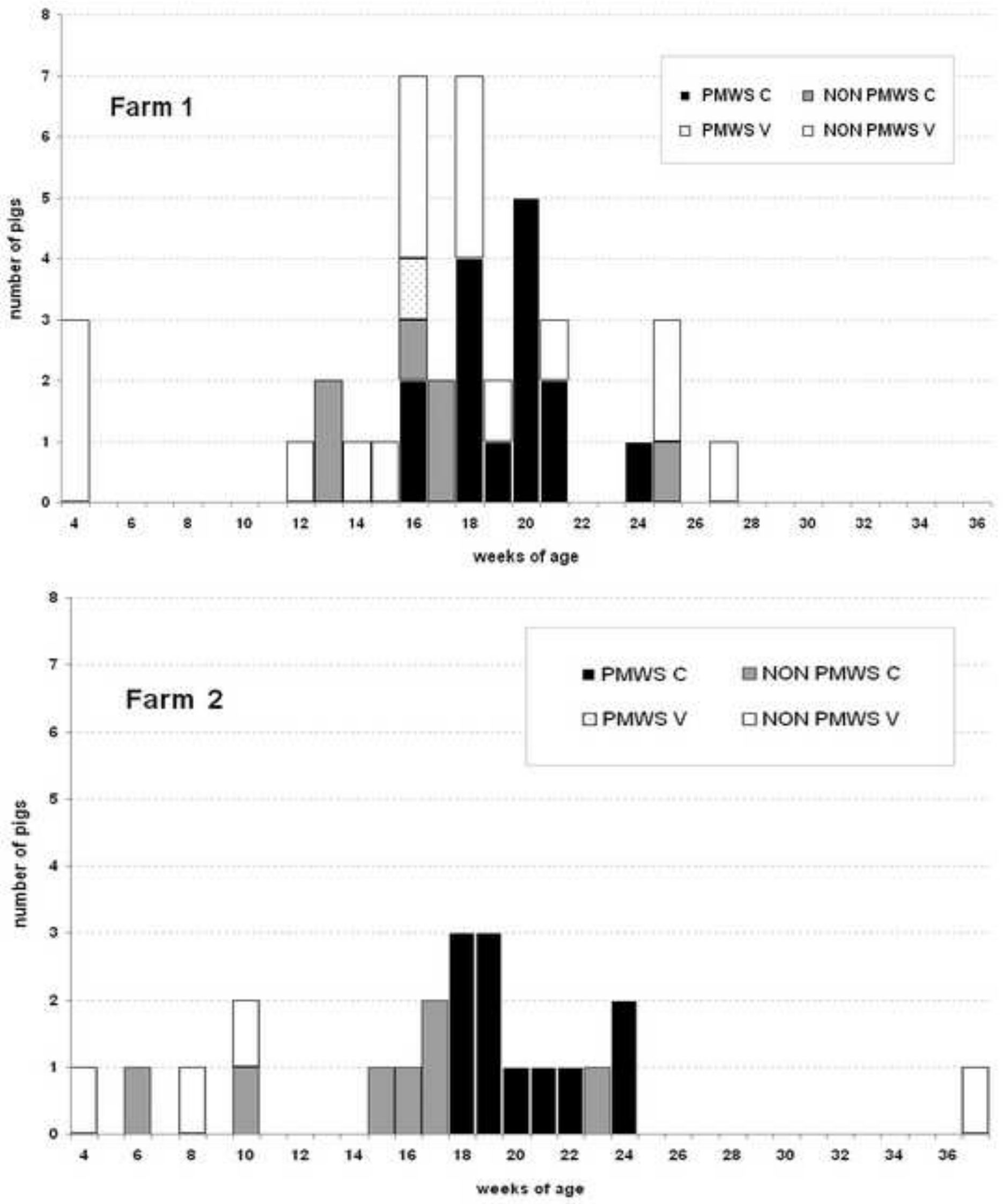

Page 34 of 39 
gure 3

Click here to download high resolution image

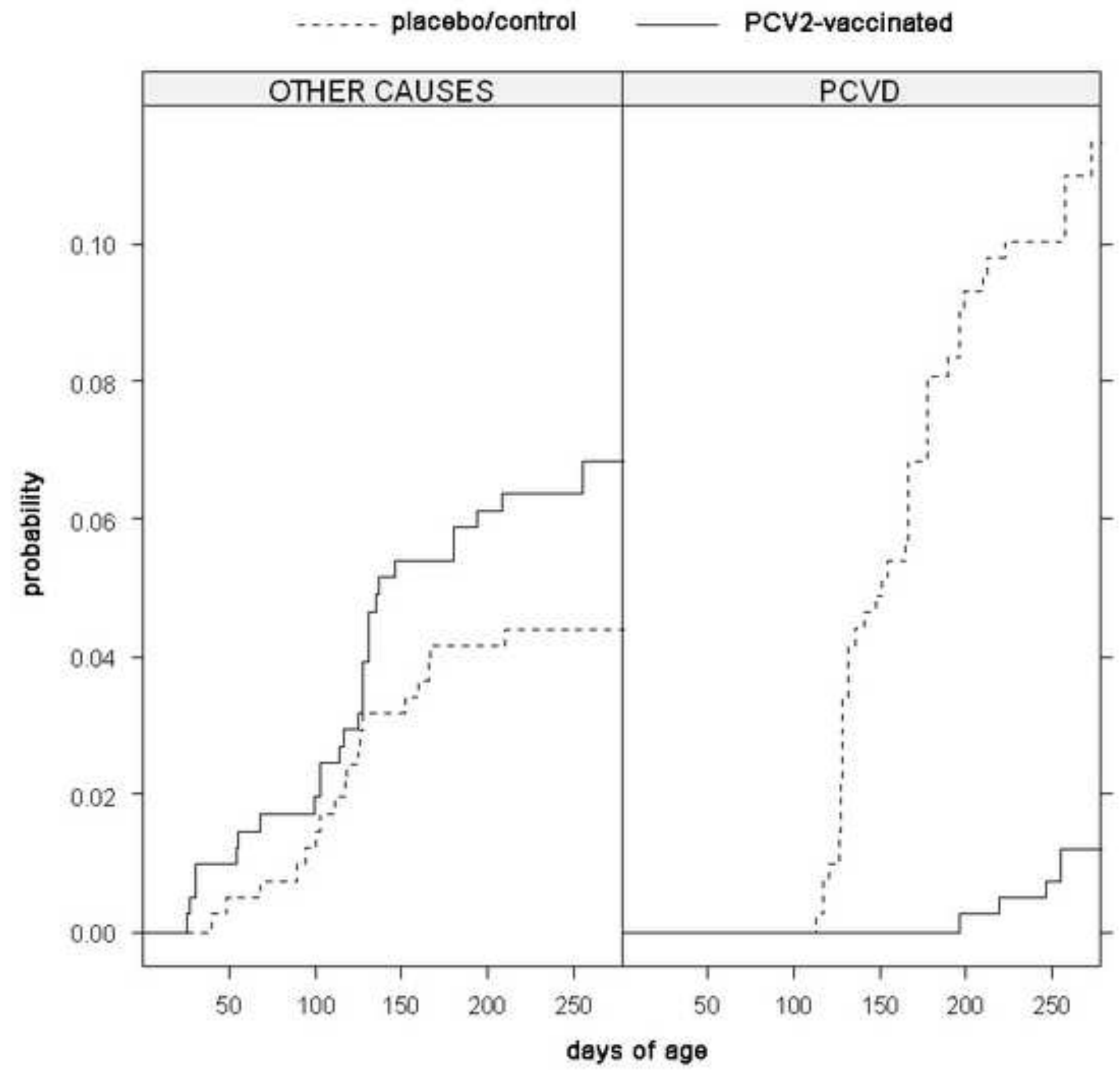

rage зל от зy 

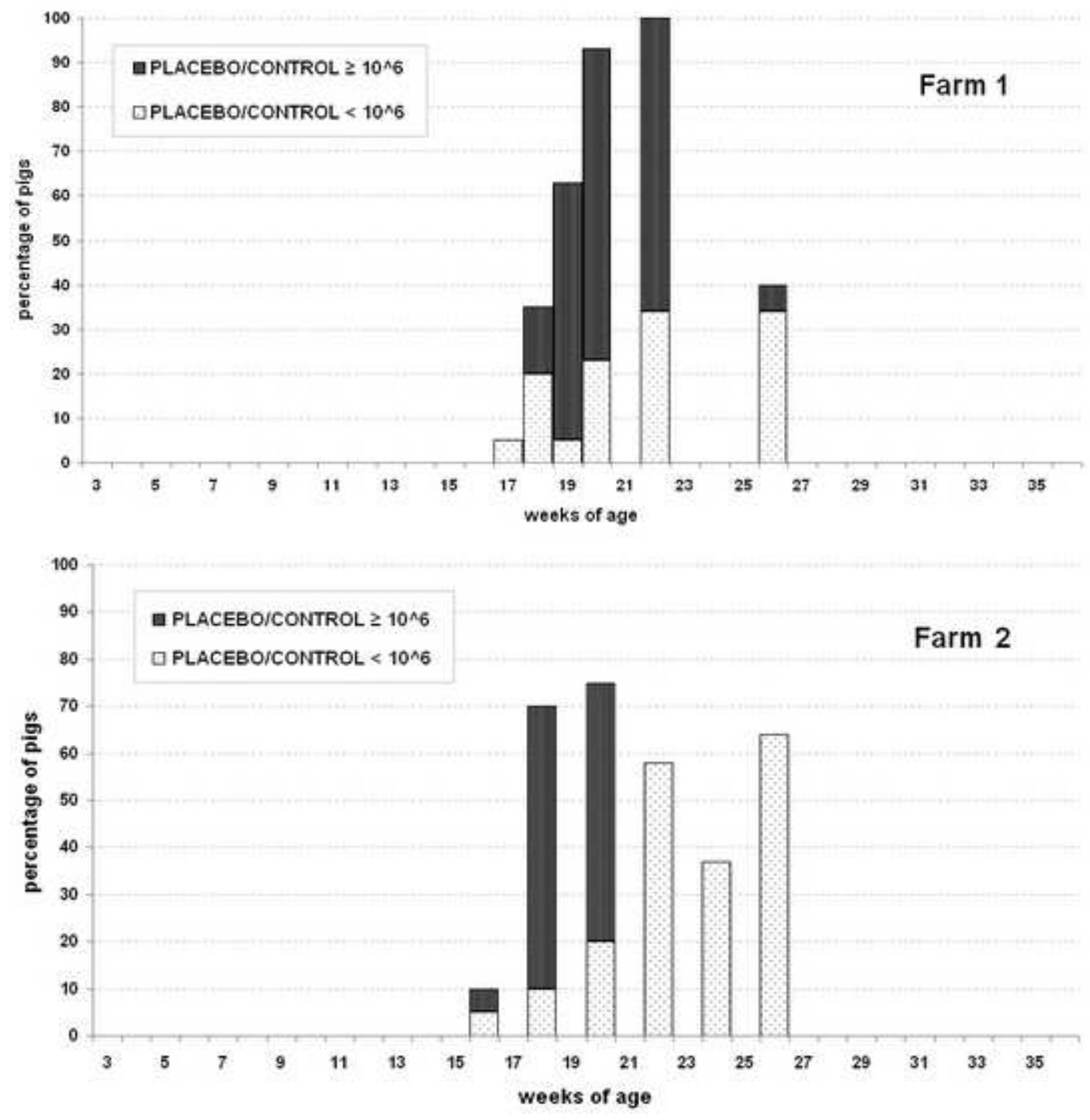

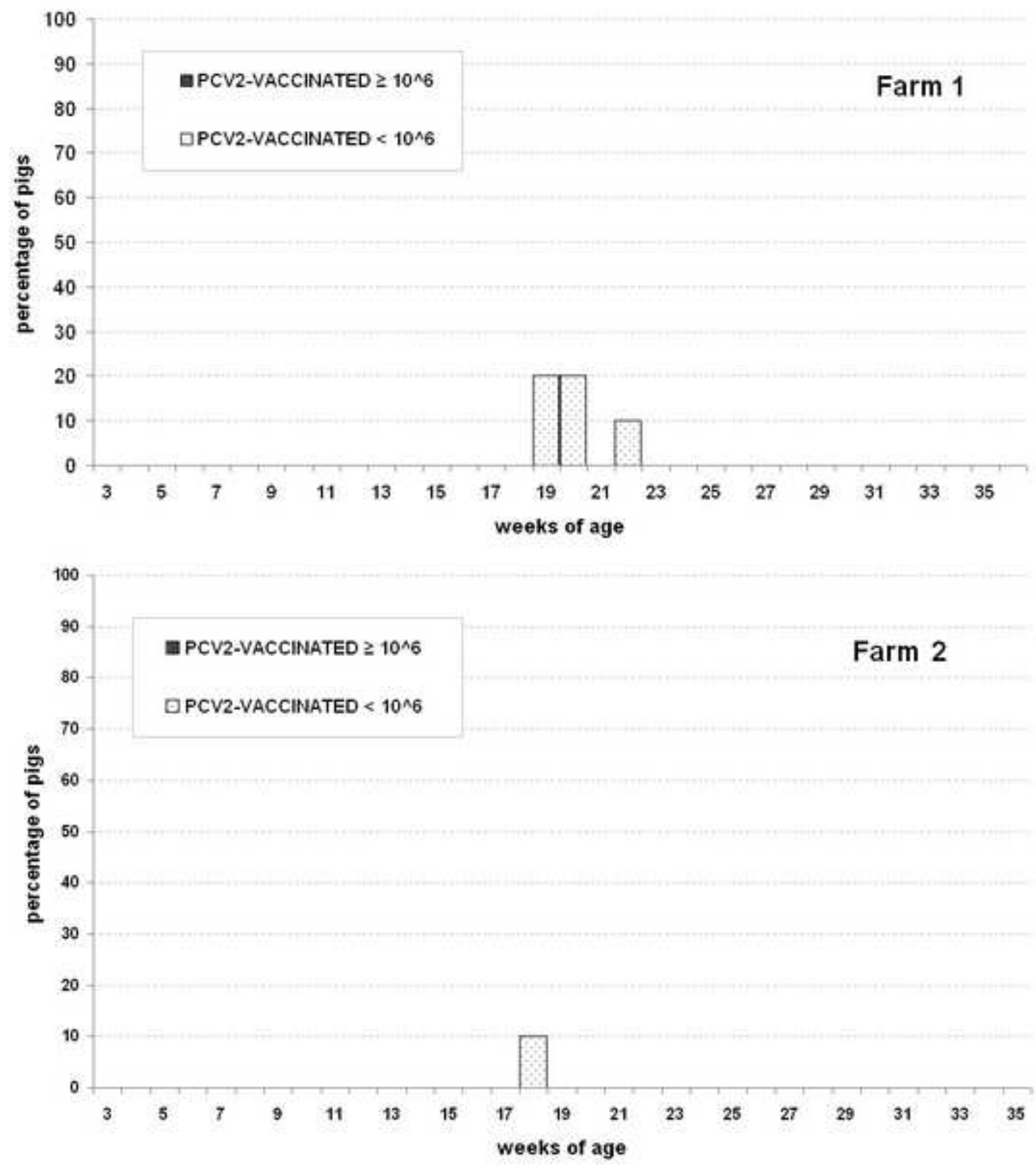
Figure 5

Click here to download high resolution image
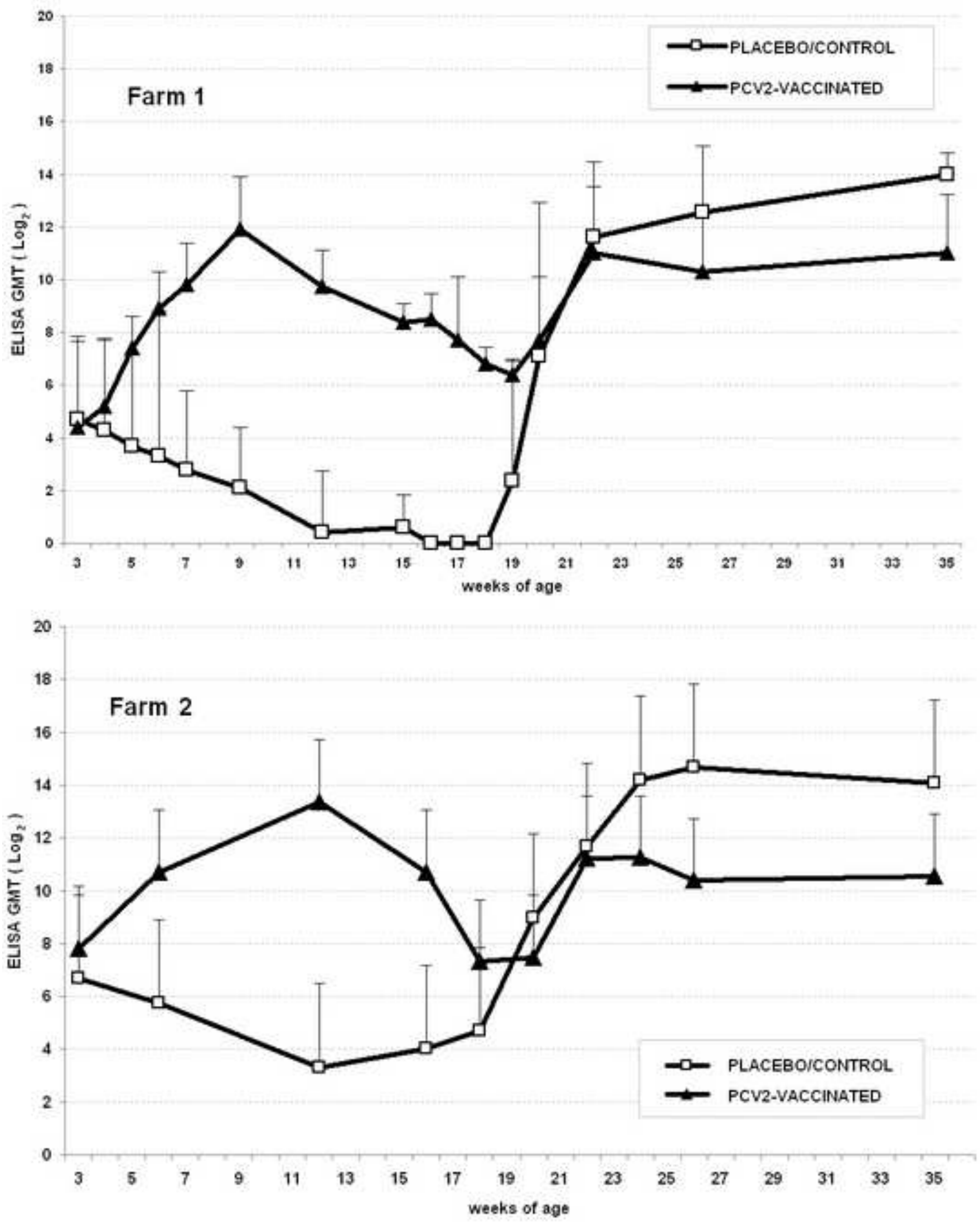

Page 38 of 39 
Click here to download high resolution image
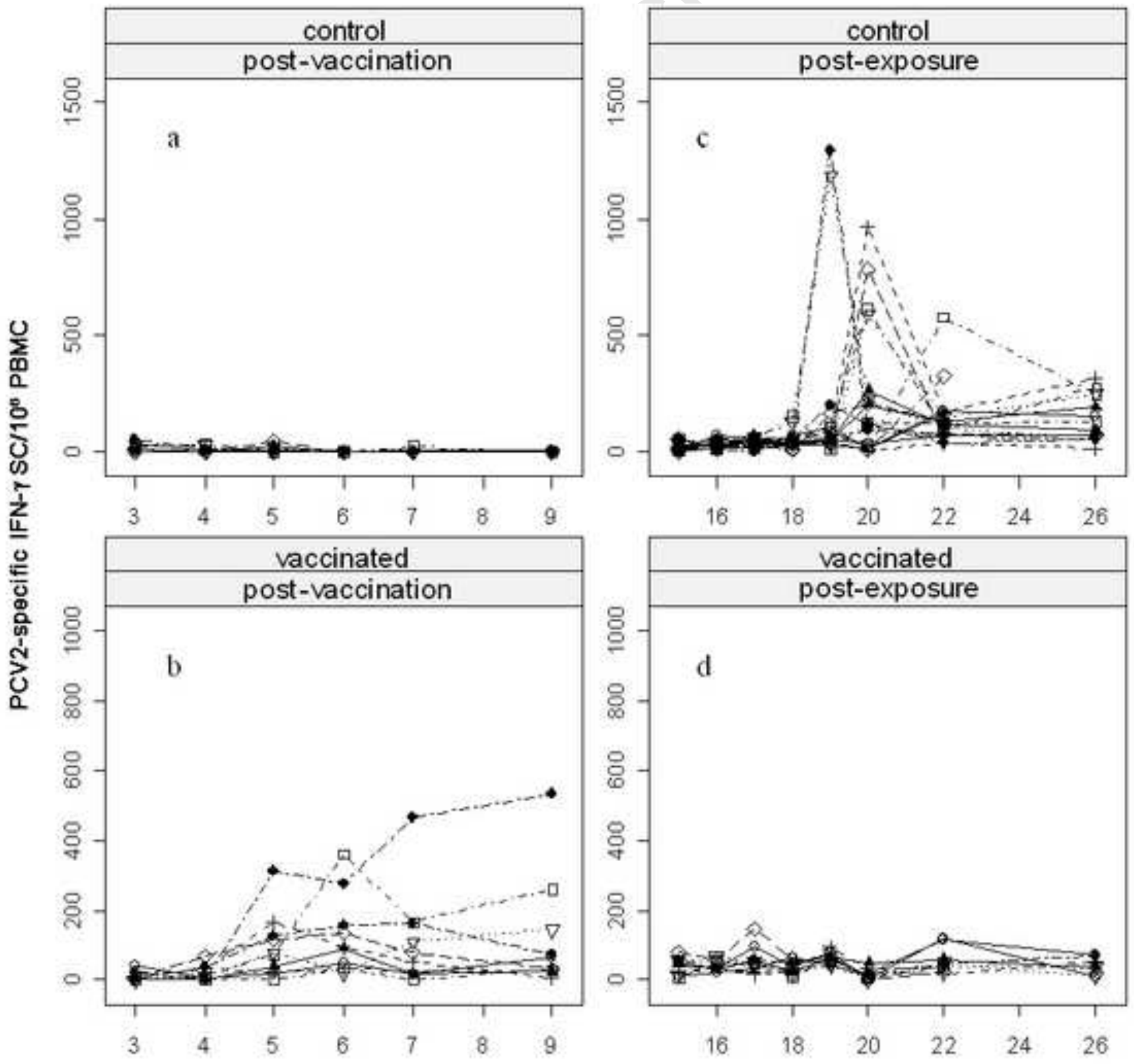

weeks of age 